\title{
Efficient transformation of chicken embryo fibroblasts by c-Jun requires structural modification in coding and noncoding sequences
}

\author{
Timothy J. Bos, ${ }^{1,2}$ Felipe S. Monteclaro, Fumihiro Mitsunobu, Alex R. Ball, Jr., Cathy H.W. Chang, \\ Tetsuji Nishimura, and Peter K. Vogt \\ Department of Microbiology, University of Southern California, School of Medicine, Los Angeles, California 90033 USA; \\ 1Department of Microbiology and Immunology, Eastern Virginia Medical School, Norfolk, Virginia 23501 USA
}

\begin{abstract}
To assess the transforming capability of the c-Jun protein, we introduced the chicken c-jun proto-oncogene into a replication competent avian retroviral expression vector (RCAS). Viral Jun efficiently transformed chicken embryo fibroblasts (CEFs) when expressed from this vector. Overexpression of $\mathrm{c}$-Jun leads to transformation of CEFs with an efficiency that is 15- to 25-fold less than that seen for $v$-Jun, suggesting that $v$-Jun contains structural features that increase its oncogenic potential relative to c-Jun. There are four structural differences between $v$-Jun and c-Jun. To determine the relative contribution that each of these structural differences between $\mathbf{v}$-Jun and c-Jun has on oncogenic activity, several deletion and substitution mutants were constructed. Each of these mutants was expressed in CEF and assayed for transformation by focus formation. Analysis of the results reveals that deletion of a region of 27 amino acids near the amino terminus of c-Jun and deletion of $3^{\prime}$ untranslated sequences are critical in activating the full oncogenic potential of Jun.
\end{abstract}

[Key Words: c-Jun; v-Jun; transformation; oncogene]

Received March 23, 1990; revised version accepted July 31, 1990.

In their normal cellular settings, the products of protooncogenes are not oncogenic. They become oncogenic when their activity within the cell is altered, resulting in a loss of control over either expression or function. This may occur through structural or functional changes in the protein, itself, or through elevated or inappropriate expression of an otherwise normal gene product. This leads to changes in gene expression and a loss of normal growth-controlling mechanisms. Because of its direct involvement in regulation of gene expression, the Jun oncoprotein provides an excellent model through which specific genetic programs involved in cell growth and tumorigenesis can be identified. In our studies, we have focused on determining the factors that control the oncogenic potential of $c$-Jun.

The product of the proto-oncogene c-jun is a major component of the AP-1 transcription complex (Bohmann et al. 1987; Angel et al. 1988b; for review, see Vogt and Bos 1989, 1990). AP-1 regulates the transcription of several genes through its ability to bind specifically to the DNA sequence TGACTCA and variations of this motif (Angel et al. 1987; Lee et al. 1987a,b). In addition to c-Jun, AP- 1 contains the product of another proto-oncogene, c-fos (Rauscher et al. 1988b; Bohmann et al. 1989;

${ }^{2}$ Corresponding author.
Curran et al. 1989|. The c-Jun and c-Fos proteins form a heterodimer through a leucine-rich region, present in both proteins, termed the leucine zipper (Halazonetis et al. 1988; Kouzarides and Ziff 1988; Nakabeppu et al. 1988; Rauscher et al. 1988a; Gentz et al. 1989; Turner and Tjian 1989). Both c-Jun and c-Fos contain functional domains that contribute to DNA binding and transcriptional regulation; however, only c-Jun is able to form homodimers that exhibit functional activity (Rauscher et al. 1988a; Turner and Tjian 1989).

$\mathrm{v}$-jun was isolated originally from avian sarcoma virus 17 (ASV 17; Maki et al. 1987). ASV 17 induces sarcomas in chickens and transforms chicken embryo fibroblasts (CEFs) in culture (Cavalieri et al. 1985). ASV 17 is a defective virus in which parts of gag and env and all of the pol sequences are replaced by parts of the transcription unit from the cellular oncogene jun (Maki et al. 1987). ASV 17 encodes one polypeptide of $65 \mathrm{kD}$, in which 220 amino acids encoded by viral gag P19 and P10 are joined in-frame to 296 jun-encoded amino acids (Maki et al. 1987; Bos et al. 1988). The resulting polypeptide is termed v-Jun. v-Jun is the oncogenic effector of ASV 17 (Ball et al. 1988).

v-Jun and c-Jun exhibit several structural differences in both coding and noncoding sequences (Nishimura and Vogt 1988). A functional comparison of v-Jun and c-Jun 
has revealed that, like c-Jun, v-Jun binds specifically to AP-1 target DNA (Bos et al. 1988), can activate transcription from AP-1 target promoters (Angel et al. 1988b), and can form a complex with c-Fos (Bos et al. 1989). In addition, overexpression of c-Jun in Rat 1 cells, primary rat embryo cells cotransfected with an activated c-Ha-ras gene (Schütte et al. 1989), or as a single gene in primary CEF results in cell transformation. Here, we show that v-Jun is $15-25$ times more efficient than c-Jun in inducing cell transformation in primary CEFs and that this difference in efficiency is due to structural alterations in both coding and noncoding sequences.

\section{Results}

Construction of $\mathrm{v}$-jun and c-jun expression vectors

The expression system chosen to analyze the oncogenic properties of $\mathrm{v}$-Jun and $\mathrm{c}$-Jun is derived from the genome of the replication-competent Prague strain of Rous sarcoma virus (RCAS) (Hughes and Kosik 1984; Hughes et al. 1987). The RCAS expression plasmid (a gift from Stephen Hughes) contains sequences of the $5^{\prime}$ and $3^{\prime}$ long terminal repeats (LTRs), complete coding information for the Gag proteins, the polymerase derived from the Bryan high titer strain of Rous sarcoma virus (RSV), and the Env proteins of subgroup A, but no oncogene. In addition, it contains a functional splice acceptor and a single ClaI cloning site $3^{\prime}$ to the env gene. When transfected into CEFs, RCAS produces an infectious retrovirus that is not transforming.

Both v-jun and c-iun were cloned into RCAS by a twostep process. Full-length copies of v-jun (VJ-O) and c-jun (CJ-1) (Fig. 1) were first cloned into an adaptor plasmid (CLA12NCO; Hughes et al. 1987), which contains a polylinker bounded by two ClaI sites to yield pAVJ-0 and pACJ-1, respectively. An NcoI site present in the polylinker was used in some cases as an ATG initiation

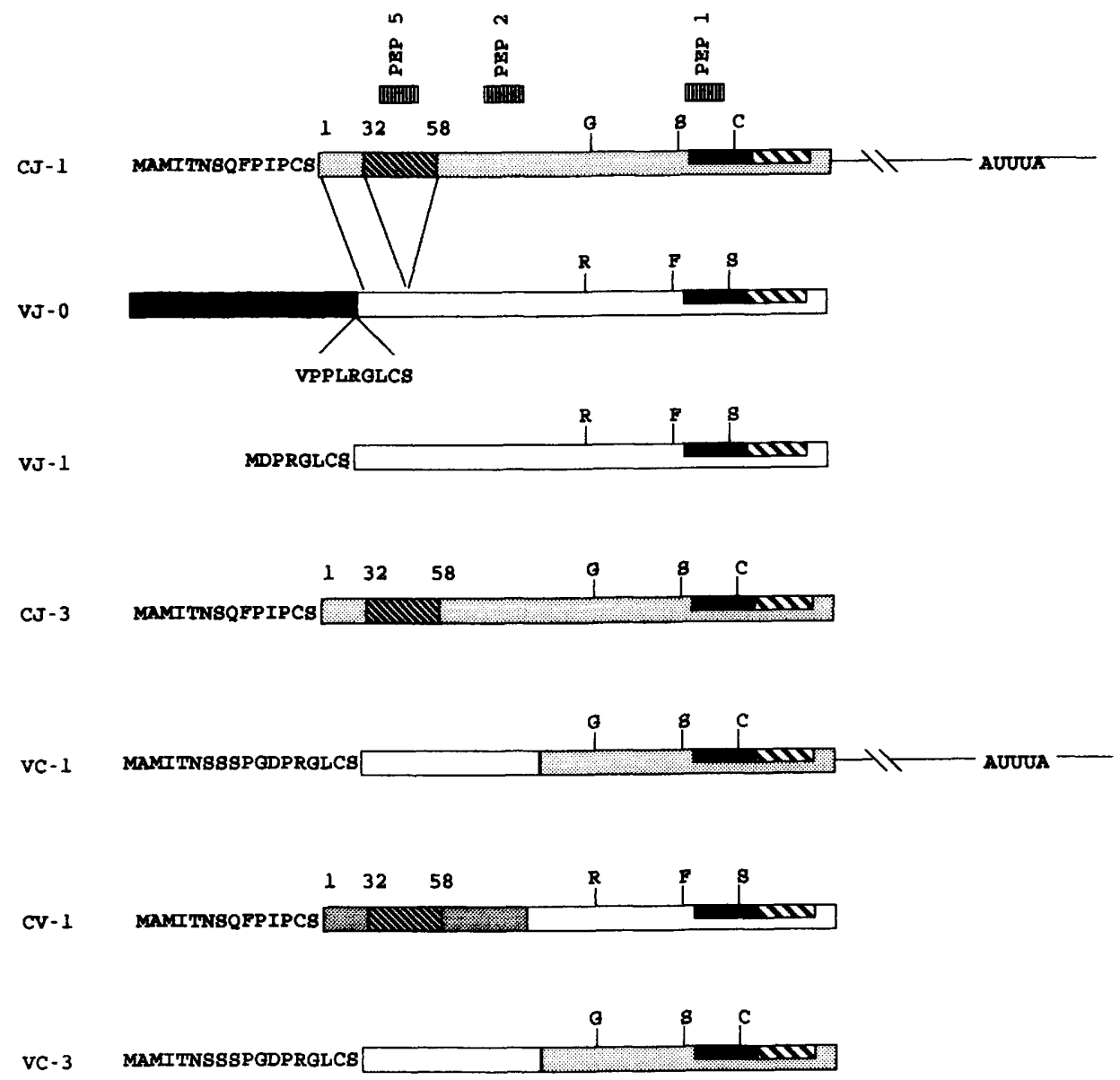

Figure 1. Structure of v-Jun, c-Jun, and Jun deletion and substitution mutants. Schematic representation of full-length v-Jun (VJ-0), $\mathrm{c}$-Jun $(\mathrm{CJ}-1)$, and Jun deletion and substitution mutants (VJ-1, CJ-3, VC-1, CV-1, and VC-3) are shown. c-Jun protein sequence is depicted by a shaded box; $v$-Jun protein sequence is depicted by an open box. Black indicates viral gag-encoded sequence. The large diagonal striped box is a 27 -amino-acid region of c-Jun deleted from v-Jun. The small, light-shaded box near the carboxyl terminus is the basic DNA-binding region. The heavy striped small box is the leucine zipper dimerization domain. The locations of synthetic peptides used to make synthetic peptide antibodies are depicted above CJ-1. Leader amino acids are represented by single-letter code at the amino terminus before the first jun-encoded methionine. Straight line at the carboxyl terminus indicates $3^{\prime}$-untranslated sequences. Numbering is according to chicken c-jun (Nishimura and Vogt 1988). 
codon (for details, see Materials and methods). An 1800bp ClaI fragment from pAVI-0 and a 1750-bp ClaI fragment from pACJ-1 were cloned into RCAS to yield RCAS VJ-0 and RCAS CJ-1. RCAS VJ-0 and RCAS CJ-1 were transfected into CEFs and assayed for expression and transformation.

\section{Expression of full-length $v$-Jun and c-Jun in CEF}

CEFs were transfected with RCAS VJ-0 or RCAS CJ-1 and overlayed until foci developed (usually between 7 and 14 days). Transfected cells were then transferred and assayed for expression of full-length v-Jun (VJ-0) and c-Jun (CJ-1) RNA and protein. RNA expression was assayed by Northern blot analysis of poly $(A)^{+}$RNA (Fig. 2). Protein expression was assayed by indirect immunofluorescence (Fig. 3) and immunoblot analysis (Fig. 4).

Three RNA species are expected from each JunRCAS construction (Fig. 2A): full-length viral genome (expected size, $7.2 \mathrm{~kb}$ plus the length of the insert); a transcript that utilizes the splice donor in gag P19 and the splice acceptor 5' of env (expected size, $3 \mathrm{~kb}$ plus the length of the insert); and a transcript that uses the splice acceptor $3^{\prime}$ of env (expected size, $0.7 \mathrm{~kb}$ plus the length of the insert $\mid$. In Figure $2 B$, poly $(A)^{+}$RNA isolated from cells transfected with RCAS VJ-0 (VJ-0) and RCAS CJ-1 (CJ-1) was hybridized to an LTR probe. In addition to the expected RNA species in VJ-0 (9.1, 4.8, and $2.7 \mathrm{~kb})$ and CJ-1 (9.1, 4.8, and $2.7 \mathrm{~kb})$, two additional RNAs were detected $(7.3$ and $3.0 \mathrm{~kb})$, which comigrate with those expected for RCAS vector alone (RCAS). This observation suggests that a portion of RCAS VJ-0 and RCAS CJ-1 viruses have lost their insert. This conclusion is supported by the disappearance of these bands when probed with jun (Fig. 2C). The large RNA species of VJ-0 is $0.5 \mathrm{~kb}$ shorter than expected. We have seen this in several other RCAS plasmids that contain, within their inserts, extra viral gag sequences. One possible explanation is that some viral rearrangement occurs because of the duplication of viral gag sequence. However, because the smaller VJ-0 RNA species is of the expected size and because a $67-\mathrm{kD}$ jun-related protein can be detected /see
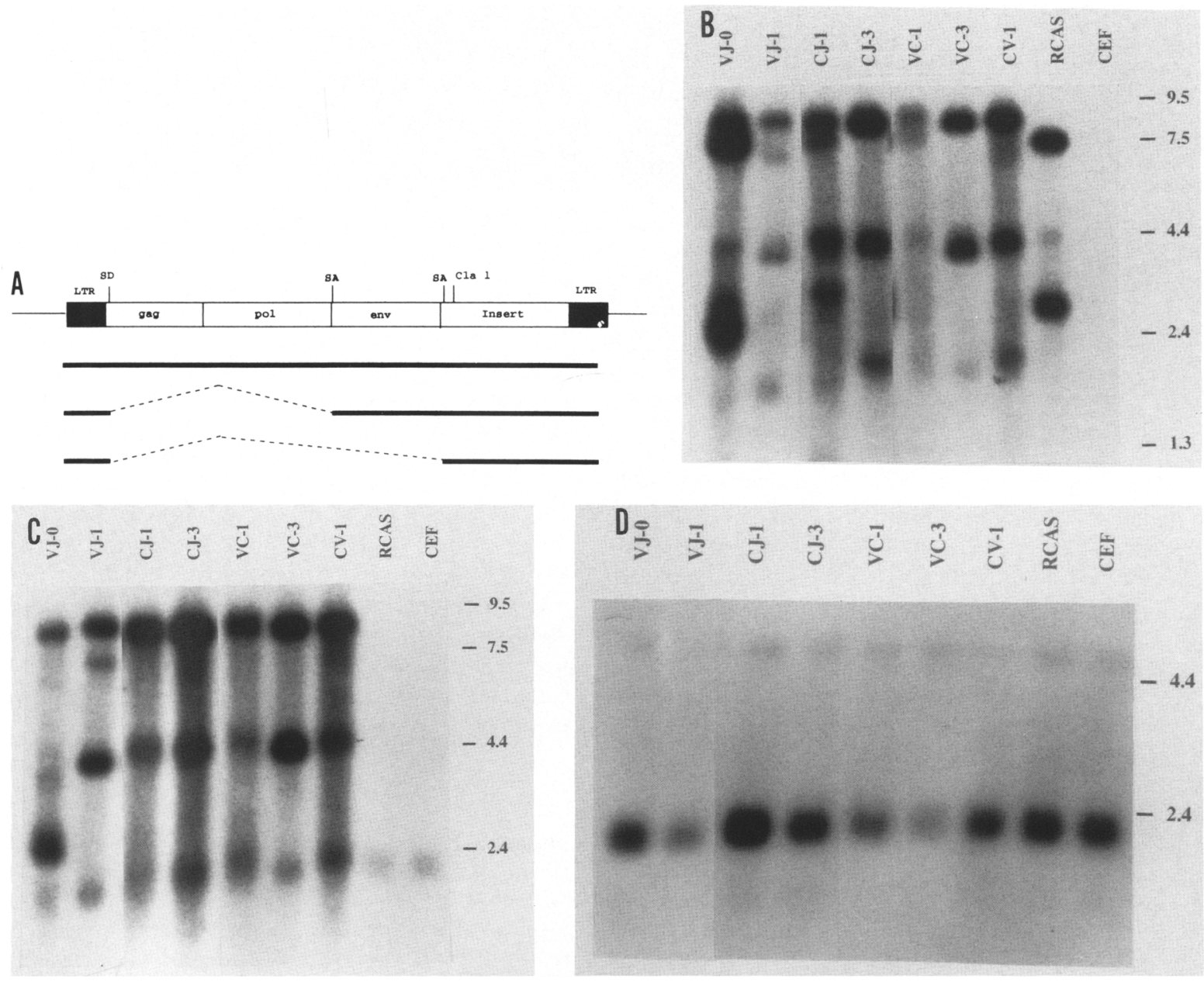

Figure 2. Northern blot analysis of v-jun, c-jun, and jun deletion and substitution mutants expressed from RCAS vectors. (A) Schematic of expected RNA sizes from Jun-RCAS constructs. Poly(A) ${ }^{+}$RNAs derived from CEFs transfected with RCAS plasmid containing v-jun (VJ-0), c-iun (CJ-1), and jun deletion and substitution mutants (VJ-1, CJ-3, VC-1, CV-1, and VC-3) were probed with LTR $(B)$, jun $(C)$, and actin $(D)$. 

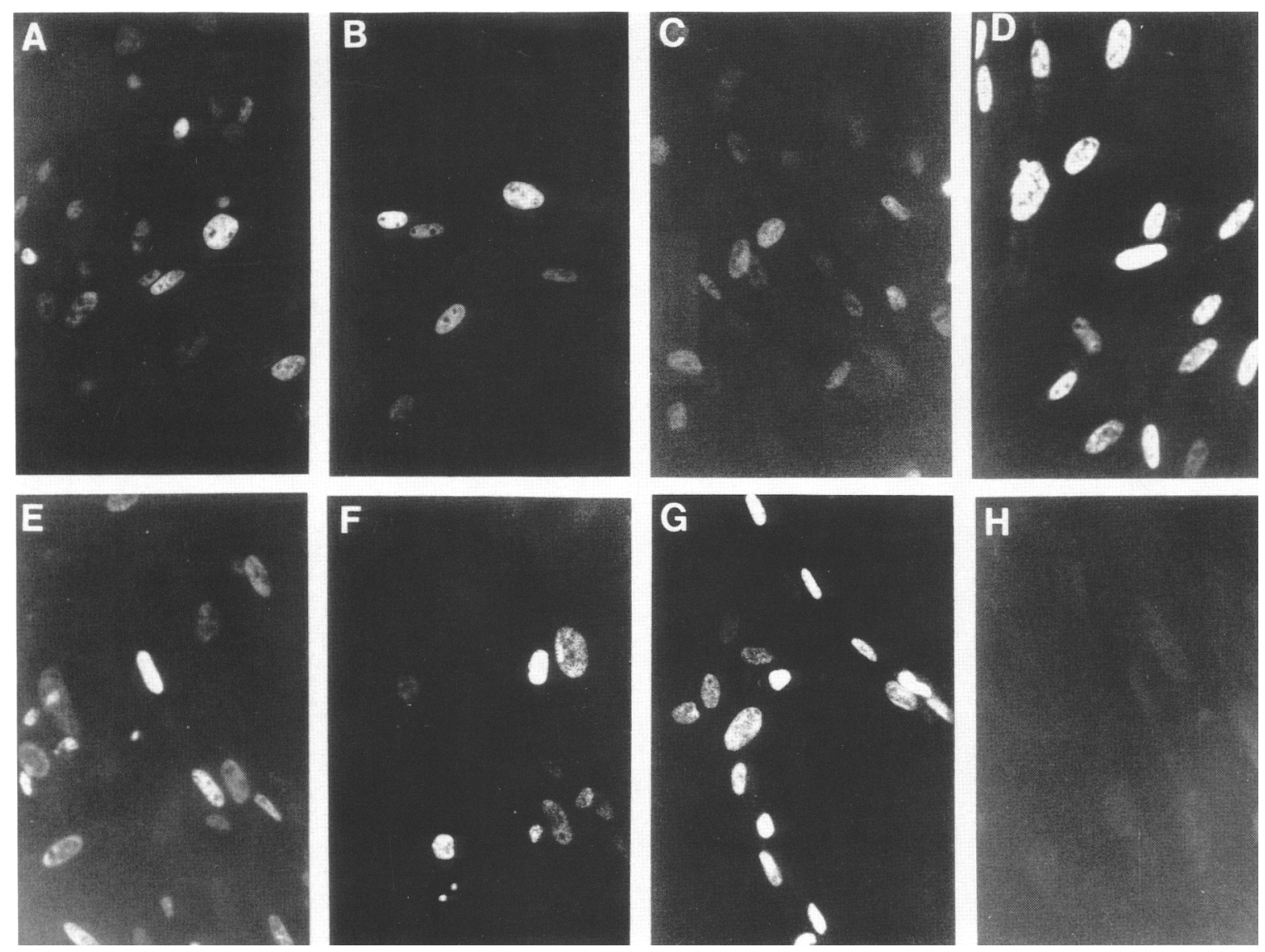

Figure 3. Immunofluorescent staining with anti-Jun antibodies. Jun protein from CEFs transfected with the following plasmids was stained with $\alpha$ PEP $2(A, B, F-H)$ or $\alpha$ PEP $5(C-E)$ antibodies. $(A)$ RCAS VJ-0; $(B)$ RCAS VJ-1; $(C)$ RCAS CJ-1; $(D)$ RCAS CJ-3; $(E)$ RCAS CV-1; $(F)$ RCAS VC-1; $(G)$ RCAS VC-3; $(H)$ RCAS.

Fig. 4A), we presume that the majority of inserts remain intact. Each of the Jun and LTR-containing RNA species from cells transfected with RCAS CJ-1 is $\sim 0.5 \mathrm{~kb}$ shorter than expected. CJ-1 contains several poly $(\mathrm{A})$ addition signals derived from c-jun (Nishimura and Vogt 1988). It is possible that the smaller RNAs detected reflect preferential use of these poly(A) addition signals.

Cells transfected with RCAS VI-0 (VJ-0) and RCAS CJ-1 (CJ-1) were assayed for Jun protein expression by indirect immunofluorescence (Fig. 3) and by immunoblot analysis (Fig. 4). A monoclonal antibody generated against the PEP 2 synthetic peptide (see Fig. 1 for location of antigen epitopes/ recognizes a domain present in both v-Jun and c-Jun. A polyclonal antibody, $\alpha$ PEP 5, was generated against a synthetic peptide representing the region deleted from v-Jun (Fig. 1). Specific nuclear staining of both v-Jun (VJ-0; Fig. 3A) and c-Jun (CJ-1; not shown/ was detected after incubation of CEF transfected with RCAS VJ-0 or RCAS CJ-1 with $\alpha$ PEP 2 monoclonal antibody. In addition, c-Jun (CJ-1; Fig. $3 \mathrm{C})$ was detected after incubation with $\alpha \mathrm{PEP} 5$, whereas no specific staining could be detected in transfected cells expressing $\mathrm{v}$-Jun (not shown). Immunoblot analysis with $\alpha$ PEP 1 (Fig. 4A) confirms VJ-0 and CJ-1 protein expression with the detection of $67-$ and $41-\mathrm{kD}$ proteins, respectively. Again, $\alpha$ PEP 5 (Fig. 4B) detects c-Jun (C)-1) but not v-Jun (VJ-0). This result demonstrates the specificity of $\alpha$ PEP 5 antibody. The band at $41 \mathrm{kD}$, which appears in VJ-0 (Fig. $4 \mathrm{~A}$ ), is generally not present and may represent a breakdown product of VJ-0. Because this band is less intense than CJ-1 when probed with $\alpha$ PEP 5 (Fig. $4 \mathrm{~B}$ ) and because immunofluorescent staining of VI-0 with $\alpha \mathrm{PEP} 5$ is always negative, we conclude that this band is not entirely endogenous $\mathrm{c}$-Jun. This observation suggests that cells transfected with RCAS VI-0 do not stimulate the expression of endogenous c-Jun.

\section{Transformation of CEF by v-Jun and c-Jun}

Figure 5 summarizes the transformation of CEFs by transfected RCAS VJ-0 and RCAS CJ-1. Typically, $50-60 \%$ of cells in a $35-\mathrm{mm}$ dish were transformed by $\mathrm{v}$-Jun (VI-0), showing $>200$ foci after transfection with $0.5 \mu \mathrm{g}$ DNA. In contrast, CEF-expressing c-Jun (CJ-1) reproducibly developed between 0 and 20 foci from the same amount of transfected DNA. In addition, typical v-Jun-induced agar colonies are compact, whereas c-Juninduced colonies are more diffuse. Examples of each are 

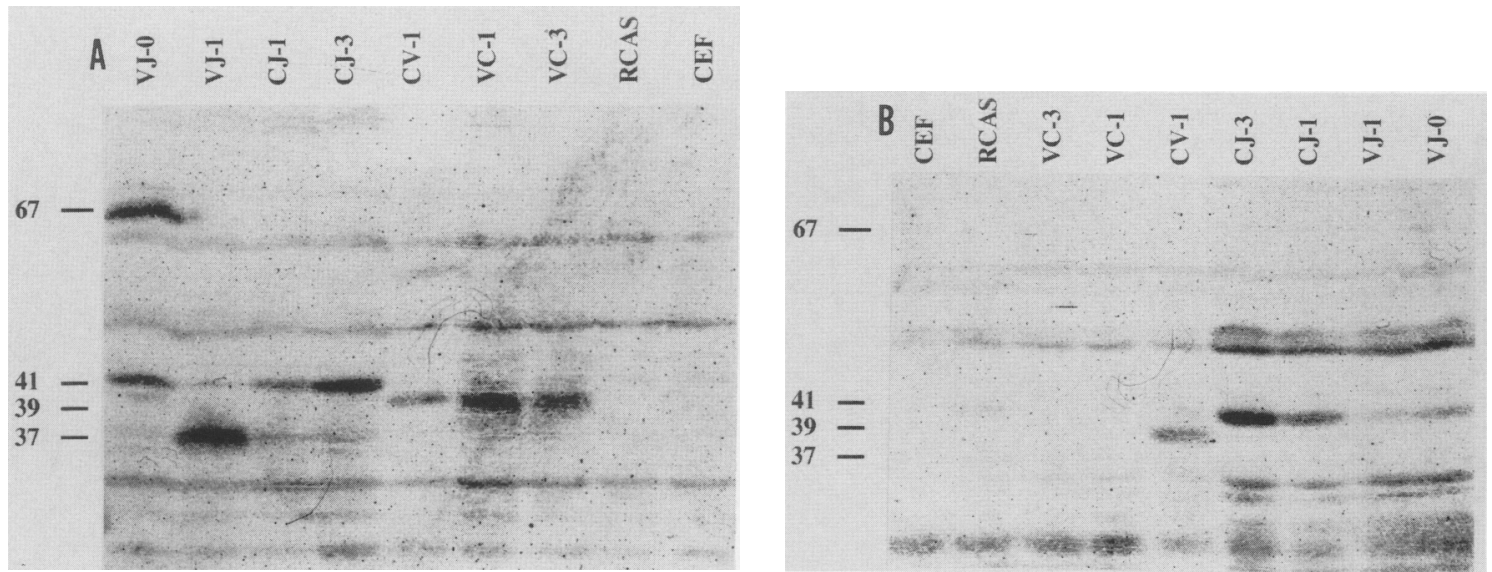

Figure 4. Immunoblot analysis of $\mathrm{v}$-Jun, c-Jun, and Jun deletion-substitution mutants expressed from RCAS vectors. Protein isolated from $\sim 2 \times 10^{6}$ CEFs transfected with RCAS plasmid containing v-jun (VJ-0), c-jun (CJ-1), and jun deletion and substitution mutants (VJ-1, CJ-3, VC-1, CV-1, and VC-3) was separated by $10 \%$ SDS-PAGE and probed with $\alpha$ PEP $1(A)$ or $\alpha$ PEP $5(B)$.

shown in Figure 6. These results suggest that a qualitative difference in structure and function between v-Jun and c-Jun is likely to play an important role in oncogenic transformation. In support of this observation, bulk virus harvested from RCAS CJ-1-transfected cells generally had a lower focus-forming titer than virus harvested from RCAS VJ-0. However, the numbers of virus particles produced and their infectivity were similar (judged by a fluorescence focus assay with anti-Env antibody that detects infected cells regardless of transformation; data not shown). Virus isolated from some, but not all, individually grown CJ-1 foci, however, yield focusforming titers similar to RCAS VJ-0. This observation suggests that some "CJ-1" foci may arise by expression from c-jun carrying mutations that increase its oncogenic potential. Studies are in progress to determine this possibility.

Effect of mutation in $v$-jun and c-jun on transformation of CEFs

Structurally, v-jun (Maki et al. 1987) differs from c-jun (Nishimura and Vogt 1988) in four areas (see Fig. 1). $\mathrm{v}$-Jun contains a 220 -amino-acid gag-encoded leader sequence, a 27-amino-acid deletion (c-Jun amino acids $32-581$, three point mutations that result in three nonconservative amino acid substitutions (at c-Jun position 185, Gly to Arg; position 226, Ser to Phe; and position 252 , Cys to Ser) near the carboxyl terminus, and a deletion of at least 630 nucleotides in the $3^{\prime}$-untranslated region, including an AUUUA sequence motif thought to be involved in mRNA destabilization.

To determine which of the structural changes in v-jun contribute toward its oncogenic activation, several deletion and substitution mutants (Fig. 1) were generated and expressed in the RCAS vector. The effect of each mutation on cell transformation was then assessed.

$\mathrm{VJ}-1$ is an amino-terminal deletion of VJ-0 in which all of the viral gag sequence and 15 nucleotides of viral jun sequence were removed. The start ATG codon for VI-1 comes from the adaptor plasmid CLA12NCO (for details, see Materials and methods). VJ-1 contains three additional jun-encoded and five linker-encoded amino

A

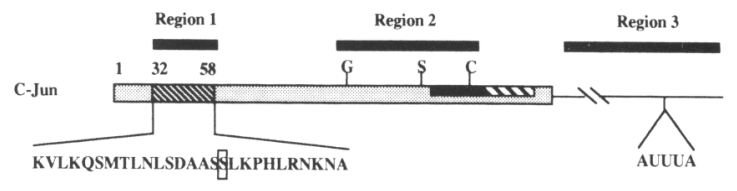

B

\begin{tabular}{rrrrrrr}
\hline & Gag & $\begin{array}{c}\text { Region 1 } \\
\text { Deletion }\end{array}$ & $\begin{array}{l}\text { Region 2 } \\
\text { Point } \\
\text { Mutation }\end{array}$ & $\begin{array}{c}\text { Region 3 } \\
\text { Deletion }\end{array}$ & $\begin{array}{c}\text { Average } \\
\text { number of } \\
\text { foci }\end{array}$ & $\begin{array}{c}\text { Fold } \\
\text { difference }\end{array}$ \\
\hline $\mathrm{VJ}-0$ & + & + & + & + & $169+1-50$ & 18.8 \\
$\mathrm{VJ}-1$ & - & + & + & + & $235+1-74$ & 26.1 \\
$\mathrm{CV}-1$ & - & - & + & + & $25+1-11$ & 2.7 \\
$\mathrm{CJ}-3$ & - & - & - & + & $56+1-22$ & 6 \\
$\mathrm{CJ}-1$ & - & - & - & - & $9+1-9$ & 1 \\
$\mathrm{VC}-1$ & - & + & - & - & $76+1-29$ & 8.5 \\
$\mathrm{VC}-3$ & - & + & - & + & $188+1-44$ & 20.9 \\
\hline
\end{tabular}

Figure 5. Effect of structural mutation on transformation efficiency of c-Jun. (A) Schematic of structural domains of c-Jun in which mutations or deletions were generated. (Region 1) A 27amino-acid domain deleted from v-Jun. Single-letter amino acid code is shown. Boxed amino acid represents a potential protein kinase C phosphorylation site. (Region 2) Domain in which three point mutations occur in v-Jun. (Region 3) 3'-untranslated RNA containing a potential destabilization signal. Other structural features are as in Fig. 1. (B) Effect on transformation of deletions in regions 1 and 3 and mutation in region 2 . 


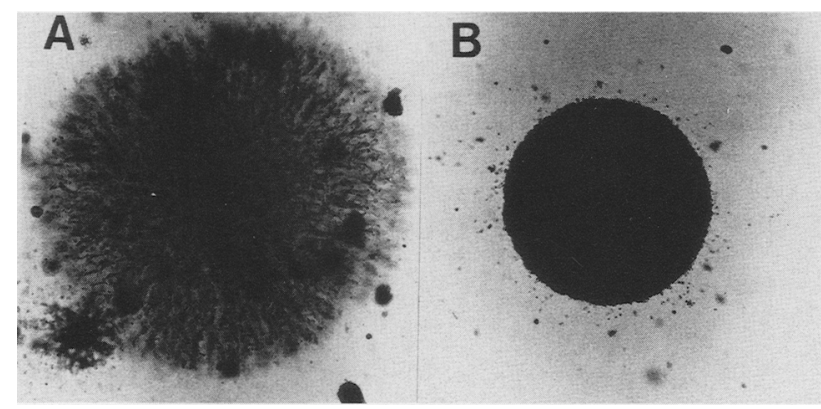

Figure 6. Formation of Jun-induced colonies in agar. (A) Agar colony formed by CEFs transfected with RCAS CJ-1; $(B)$ agar colony formed by CEFs transfected with RCAS VI-1.

acids at the extreme amino terminus before the first jun-encoded methionine (see Fig. 1). CJ-3 is identical to CJ-1, except that 608 nucleotides in the $3^{\prime}$-untranslated region have been removed. VC-1 is a chimera in which the amino terminus of VJ-1 was joined at the internal Ncol site to the carboxyl terminus of CJ-1 . VC-1 differs from full-length c-Jun $(\mathrm{CJ}-1)$ in that it contains a deletion of c-Jun amino acids $32-58$. CV-1 is a chimera in which the amino terminus of $\mathrm{CJ}-1$ is joined to the carboxyl terminus of VJ-0. CV-1 differs from CJ-1 in that it contains three point mutations (c-Jun positions 185,226 , and 252) in the carboxyl terminus (Fig. 1) and a deletion of the $3^{\prime}$-untranslated sequence. VC-3 is identical to VC-1 except that 608 nucleotides in the 3 '-untranslated region have been removed. VC-3 thus contains two deletions: one of 27 amino acids near the amino terminus (c-Jun amino acids $32-58$ ) and the other, 608 nucleotides of 3 '-untranslated sequence.

VI-1, CJ-3, VC-1, CV-1, and VC-3 were each cloned into adaptor plasmids, as described in Materials and methods, and then into RCAS to yield RCAS VJ-1, RCAS CJ-3, RCAS VC-1, RCAS CV-1, and RCAS VC-3, respectively. Each was then transfected into CEF and assayed for expression and transformation. The results of expression are presented in Figures 2-4.

Except as described below, the expected RNAs from VJ-1 $(8.3,4.0$, and $2.0 \mathrm{~kb}), \mathrm{CJ}-3(8.4,4.1,2.0 \mathrm{~kb})$, VC-1 $(9.0,4.7$, and $2.6 \mathrm{~kb}), \mathrm{CV}-1(8.5,4.2$, and $2.1 \mathrm{~kb})$, and VC-3 $(8.3,4.0$, and $2.0 \mathrm{~kb})$ were found for each construct (Fig. 2B,C). In addition to the expected RNA patterns, VJ-1 showed a band of $7.2 \mathrm{~kb}$ when probed with both LTR and jun. Because this RNA species hybridizes with LTR and jun probes, it is unlikely that it represents a Jun-RCAS virus that has lost its insert. However, it may indicate that a proportion of this virus has undergone some rearrangement. The majority of RNA, however, is the correct size, and the expected protein of 37 $\mathrm{kD}$ is expressed (Fig. 4A). We have seen similar patterns with other v-jun amino-terminal deletion mutants (data not shown). The RNA species detected in RCAS CJ-3transfected cells are expected to be $0.6 \mathrm{~kb}$ smaller than those from cells transfected with RCAS CJ-1. In Figure 2, B and C, however, CJ-3 and CJ-1 appear to be the same size. As mentioned previously, CJ-1 contains several extra poly(A) addition signals not present in CJ-3, which may be preferentially utilized leading to transcripts $\sim 0.5$ $\mathrm{kb}$ smaller than expected. This would lead to RNA species in CJ-3 and CJ-1 of the same size. The RNA patterns detected in RCAS VC-1-transfected cells are also $0.5 \mathrm{~kb}$ smaller than predicted. VC-1, however, also contains c-iun poly $(\mathrm{A})$ addition signals. Interestingly, the amount of accumulated message for CJ-3 is four times higher than for CJ-1 (measured by densitometry and normalized to actin). This is consistent with removal of a putative destabilization signal in the 3 '-untranslated region. Relative amounts of RNA loaded in each lane were determined by hybridization with an actin probe (Fig. 2D).

VJ-1, CJ-3, VC-1, CV-1, and VC-3 protein expression was assayed by indirect immunofluorescence (Fig. 3) and immunoblot analysis (Fig. 4). All mutant and wild-type proteins are expressed well above background levels. In addition, the portion of cells expressing mutant and wild-type Jun proteins is roughly equal. VJ-0, CJ-1, VJ-1, CJ-3, VC-1, CV-1, and VC-3 are expected to encode proteins of 516,324,294,324,304, 324, and 304 amino acids, respectively. By Western blot analysis, proteins of $67,41,37,41,39,39$, and $39 \mathrm{kD}$ were detected for VJ-0, CJ-1, VI-1, CJ-3, VC-1, CV-1, and VC-3, respectively (Fig. 4A). Equivalent amounts of protein were loaded in each lane, as judged by staining with Coomassie blue (not shown). Figure $4 B$ is presented to show the specificity of the $\alpha$ PEP 5 antibody. In Figure 4B, VJ-0, VI-1, CJ-1, and CJ-3 contain equivalent amounts of protein, as judged by staining with Coomassie blue (not shown). CV-1, VC-1, VC-3, RCAS, and CEF also contain equivalent amounts of protein, although lower than VJ-0, VJ-1, CJ-1, and $\mathrm{CJ}-3$. As expected, only those mutants that contain c-Jun amino termini are detected with the $\alpha$ PEP 5 antibody (Figs. 3C-E and 4B).

The effect of expression of VI-1, CJ-3, VC-1, CV-1, and VC-3 on cell transformation is presented in Figure 5. Expression of VJ-1 results in transformation consistently higher than that induced by full-length v-Jun (VJ-0). Typically, $80-100 \%$ of the cells in a $35-\mathrm{mm}$ dish were transformed after transfection of $0.5 \mu \mathrm{g} \mathrm{VJ-1}$ DNA. This implies that the 220-amino-acid gag-encoded leader at the amino terminus of $\mathrm{v}$-Jun is neither required nor necessary for efficient transformation and may actually be attenuating because transformation is higher in its absence. Removal of the $3^{\prime}$-untranslated sequence from c-jun in CJ-3 increased the transformation efficiency of c-Jun sixfold. CJ-3 reproducibly generated between 20 and 80 foci per $0.5 \mu \mathrm{g}$ DNA. The number of foci induced by expression of VC-1 is 8.5 -fold higher than that seen for CJ-1. VC-1 typically gives rise to $40-120$ foci per 0.5 $\mu \mathrm{g}$ DNA. The transformation efficiency of CV-1 was similar to that of CJ-3. Interestingly, the VC-3 mutant, which combines deletion of c-Jun amino acids $32-58$ with a deletion of the $3^{\prime}$-untranslated sequence, restored wild-type v-Jun-transforming capability. These data suggest that specific structural alterations in v-Jun contribute to its ability to transform CEF. Both deletion of coding (amino acids $32-58$ ) and noncoding sequences 
contribute to activation of the oncogenic potential of Jun.

\section{Discussion}

Three general conclusions can be drawn from the data presented in this paper: (1) Overexpression of c-Jun results in transformation of CEF; (2) v-Jun is 15-25 times more efficient at inducing cell transformation than c-Jun; and (3) both deletion of c-Jun amino acids 32-58 and deletion of $3^{\prime}$-untranslated sequence contribute to full activation of the oncogenic potential of c-Jun (Fig. 5).

What are the functional properties associated with these two domains? The function of the $3^{\prime}$-untranslated sequences of c-jun are not known; however, they are likely to exert some type of post-transcriptional (turnover) or translational control of Jun. In chicken c-jun, the $3^{\prime}$-untranslated sequence is $\sim 660$ nucleotides long, contains two poly(A) addition signals, one AUUUA, and several AUUUUA sequence motifs (Nishimura and Vogt 1988). AUUUA motifs have been found in several genes and are thought to destabilize mRNA (Shaw and Kamen 1986; Lee et al. 1988; Shyu et al. 1989|. Consistent with this function, removal of these sequences from c-jun in CJ-3 increases the steady-state level of poly(A) ${ }^{+}$ c-jun RNA in the cell fourfold (cf. CJ-1 and CJ-3 in Fig. $2 \mathrm{~B}-\mathrm{D})$. In addition, protein expression is also increased (Figs. 3 and 4) to a level at least as high as viral Jun; however, transforming activity increases only sixfold. This is still three- to fourfold lower than viral Jun. Clearly, the level of expression of c-Jun is important in oncogenic transformation; however, it does not appear to be the only factor involved. With the paired viruses VC- 1 and VC-3, which differ only by removal of 3 '-untranslated sequences, we do not see a major difference in levels of protein expression and only a 2.5 -fold difference in transformation activity. The reason for this is not clear. If, as we speculate below, removal of amino acids $32-58$ derepresses a negative regulation domain, a small increase in expression of "active" Jun could lead to a significant increase in oncogenic activity. In our system, the elevation in expression may be very slight and not detectable. In addition, removal of Jun amino acids 32-58 may attenuate the function of $3^{\prime}$-untranslated sequences. Alternatively, the Jun protein may not be able to exceed a certain level before it becomes toxic.

The observation that deletion of amino acids $32-58$ is critical in promoting oncogenic activity in Jun suggests that this region contains an important control element. Whether the entire region or only a few specific amino acids are involved is currently not known. Bohmann and Tjian (1989) have recently found this same region to contain a negative transcription regulatory element. This conclusion is supported by their observation that equal amounts of v-Jun and c-Jun bacterial-expressed protein differed in their ability to stimulate transcription from an AP-1 responsive element in an in vitro transcription assay. Whereas both v-Jun and c-Jun were able to bind to DNA with equal affinity, v-Jun was sig- nificantly more active in activating transcription. In addition, a deletion analysis of c-Jun showed that removing the region between amino acids 23 and 92 of c-Jun resulted in an increase in transcriptional activation, suggesting that c-Jun contained a negative regulator of transcription. In the data presented here, we show that deletion of this same region is required for full activation of the oncogenic potential of c-jun. These results imply that c-Jun may exist within the cell in transcriptionally active and inactive forms and that v-Jun may represent a constitutively active form of $c$-Jun. The precise function of this domain remains to be worked out. Some possibilities include regulation through phosphorylation or dephosphorylation, glycosylation, or protein-protein interactions. Lüscher et al. (1990) have shown recently that a phosphorylation event in the $\mathrm{c}-\mathrm{Myb}$ proto-oncogene product can act as a negative regulator by inhibiting DNA binding. Interestingly, c-Jun contains several potential protein kinase $\mathrm{C}$ phosphorylation sites. One of these sites resides within amino acids $32-58$ at Ser-48 in the chicken c-Jun protein (see Fig. 5). It is not known whether this site is used. Studies designed to determine the minimum sequence required in this region are currently under way.

Mutation at c-Jun amino acids 185, 226, and 252 does not appear to play a major role in oncogenic transformation by Jun. This is shown by the finding that the oncogenic activity of $\mathrm{CV}-1$ is no higher than CJ-3 (Fig. 5). CV-1 differs from CJ-3 by mutation at residues 185,226 , and 252.

The activity of c-Jun may be regulated at a number of levels. Besides the transcriptional level, post-translational modifications may be involved both in regulating DNA-binding affinity (Angel et al. 1987; Lee et al. 1987a) and transcriptional regulatory capabilities (Bohmann and Tjian 1989|. Thus, c-Jun may exist in active and inactive forms. Although both forms may bind to DNA, perhaps only the active form is able to regulate the transcription of specific target genes. Overexpression of c-jun could then lead to accumulation of protein levels, quantitatively similar to v-Jun; however, the proportion of active Jun may be significantly smaller. Alternatively, differences in transcriptional regulation between $\mathrm{v}$-Jun and c-Jun in vitro may reflect a difference in transcriptional specificity rather than overall activity. For example, v-Jun may activate specific promoters that c-Jun normally represses, or vice versa.

In a separate set of experiments, Schütte et al. (1989) have shown that overexpression of human c-jun (lacking 3 '-untranslated sequences) in Rat 1 cells leads to cell transformation and tumorigenesis; however, transformation of primary rat embryo cells requires the expression of an activated ras gene in addition to c-jun. Ras has been implicated in the activation of transcription of genes under the control of AP-1 such as collagenase and transin (stromelysin) (Imler et al. 1988; Schönthal et al. 1988; Sistonen et al. 1989|. This suggests that the Rasinduced pathway activates c-Jun, either through transcription of the c-jun gene or by activation of the c-Jun protein. Here, we show that a requirement for activated 
Ras is not necessary for induction of transformation by v-Jun or c-Jun in primary CEF. Whether activated Ras can increase the transformation efficiency of c-Jun in CEF has not yet been tested.

c-jun is under many controls, including transcriptional, post-transcriptional, and post-translational. Transcription of c-jun is stimulated, depending on the cell type, by a variety of factors, including serum, epidermal growth factor (EGF), platelet-derived growth factor (PDGF), transforming growth factor $\beta$ (TGF $\beta$ ), nerve growth factor (NGF), tumor necrosis factor (TNF), and 12-O-tetradecanoyl phorbol 13-acetate (TPA) (Lamph et al. 1988; Quantin and Breathnach 1988; Ryder and Nathans 1988; Bartel et al. 1989; Brenner et al. 1989; Pertovaara et al. 1989|. Post-translational control of c-Jun activity has been seen in several systems. AP-1 (which contains c-Jun as a major component) was identified originally as a protein complex that bound to responsive elements after treatment with TPA (Angel et al. 1987; Lee et al. 1987a). Activation of the DNAbinding activity of AP-1 in HeLa cells by TPA occurred even in the presence of cycloheximide, indicating that a post-translational modification of AP-1 had occurred. c-Jun activity is also modulated by means of proteinprotein interactions. c-jun and c-fos belong to multigene families, each containing at least two other members. In addition to c-jun; junB (Ryder et al. 1988) and junD (Hirai et al. 1989) have recently been cloned and sequenced. Likewise, several fos-related antigens have been identified (Fra-1 (Cohen and Curran 1988) and FosB [Zerial et al. 1989)]. Each member of the jun family is capable of interaction with members of the fos family (Nakabeppu et al. 1988; Cohen et al. 1989). Furthermore, c-Jun can form homodimers that bind to DNA, albeit with lower efficiency than Jun/Fos heterodimers (Halazonetis et al. 1988; Nakabeppu et al. 1988; Rauscher et al. 1988a). AP-1 has been shown to contain, in addition to c-Jun and c-Fos, small quantities of JunB and Fra-1 (Bohmann et al. 1989; Curran et al. 1989; Cohen et al. 1989). Thus, AP-1 contains a number of proteins, each capable of multiple protein-protein interactions. The different protein-protein combinations may exhibit subtle differences in substrate specificity or regulatory capacities.

c-jun has also been reported to up-regulate its own transcription in F9 cells (Angel et al. 1988a). We have found that expression of v-Jun in CEF does not lead to constitutive positive autoregulation of c-jun (see Fig. 4). None of the cells expressing various RCAS-iun constructs (other than CJ-1 and CJ-3) appear to express endogenous c-Jun over background levels (Fig. 4A). As discussed in Results, the $41-\mathrm{kD}$ band in VI-0 (Fig. 4A) is generally not present and is likely a breakdown or truncated version of VI-0 from this particular extract. This is supported by the low intensity of this band when probed with the c-Jun-specific $\alpha$ PEP 5 antibody in Figure 4B. Because RCAS CJ-1 and RCAS CJ-3 transcripts (Fig. 2) comigrate with endogenous c-Jun, it is not clear whether they also do not induce endogenous c-Jun or whether its expression is merely masked. Because autostimulation of c-jun through the AP-1 site is transient, it is not clear whether v-Jun actually does not stimulate c-jun or whether we were unable to detect it because of its transient nature. In either case, it appears that continuous autostimulation of c-jun by v-Jun is unlikely to play an important role in oncogenesis.

Clearly, the mechanism by which Jun induces cell transformation is complex. The experiments that we have described in this report define the structural properties of Jun required for cell transformation. The specific pathways, interactions, and targets involved remain to be determined.

\section{Materials and methods \\ Construction of $v$-Jun, c-Jun, and Jun deletion and substitution expression vectors}

The expression plasmid RCAS VI-0 was derived by insertion of an 1800-bp ClaI insert from pAVT-0 into the ClaI site of RCAS (Hughes and Kosik 1984; Hughes et al. 1987). pAVJ-0 was derived by insertion of a DNA fragment containing the entire coding domain of p65gag-iun into the SmaI site of CLA12NCO (Hughes et al. 1987). This fragment, extending 29 nucleotides upstream of the viral P19 gag start codon and ending $125 \mathrm{nu}$ cleotides $3^{\prime}$ of the TGA stop codon in Jun, was generated by restriction with $X b a \mathrm{I}$ and EcoRI, followed by DNA polymerase I of the BAL-31 deletion clone 5-5 (in M13mp18) from ASV 17 clone 241-26-1 (Maki et al. 1987). RCAS VJ-1 was derived by cloning a 1047-bp ClaI insert from pAVJ-1 into the ClaI site of RCAS. pAVJ-1 was derived by cloning fragments generated by digestion with EcoRI/PolI and BamHI of BAL-31 deletion clone 4-26 (in M13mpl8) between the BamHI, and HindIII/Poll sites in CLA12NCO, which had previously been restricted with $\mathrm{NcoI}$ and BamHI followed by DNA polymerase I and religation. The ATG start codon is provided by the NcoI cloning site. RCAS CJ-1 was obtained by cloning the 1750 -bp ClaI insert of pACJ-1 into RCAS. pACJ-1 contains the entire coding sequence of the chicken c-jun cDNA (Nishimura and Vogt 1988). A BamHI-EcoRI fragment from M13mp18 clone A2, extending 26 nucleotides $5^{\prime}$ of the putative ATG start and ending $678 \mathrm{nu}-$ cleotides $3^{\prime}$ of the TGA stop, was excised, made blunt with DNA polymerase I, and cloned into the SmaI site of pUC8 to yield pUC8CJ-1. The c-jun insert in pUC8CJ-1 was excised with EcoRI/PolI and HindIII, and this fragment cloned between SmaI and HindIII in pUC8 to yield pUC8CJ-2. Finally, the c-jun insert from pUC8CI-2 was excised by restriction with EcoRI and BamHI and cloned into CLAl2NCO between EcoRI and BamHI. This construction can utilize the ATG start provided by $N c o$ I to yield a fusion protein containing 14 amino acids at the extreme amino terminus before the first c-jun-encoded methionine (see Fig. 1). RCAS CJ-3 was obtained by cloning the 1134-bp ClaI insert of pACJ-3 into RCAS at the ClaI site. pACJ-3 was constructed by restriction of pACJ-1 with MluI and BamHI, followed by DNA polymerase I and religation. RCAS VC-1 was obtained by cloning the 1678-bp ClaI insert from pAVC-1 into RCAS at ClaI. pAVC-1 was constructed by ligating a 366-bp NcoI-SalI fragment of pACJ-1 and a 1181-bp Ncol-BamHI fragment of pAVJ-1 into CLA12NCO between BamHI and Sall. RCAS CV-l was obtained by cloning the 1180-bp ClaI insert of pACV into RCAS at the ClaI site. pACV was constructed by ligating a 443-bp NcoI-EcoRI fragment of pACJ-1 and a 610-bp NcoI-Sall fragment of pAVI-0 into CLA12NCO between EcoRI and Sall. RCAS VC-3 was obtained by cloning the 1050-bp ClaI insert of pAVC-3 into the ClaI site 
of RCAS. pAVC-3 was constructed by removing a 628-bp fragment in pAVC-1 by restriction with MluI and SalI, followed by DNA polymerase I and religation.

\section{Preparation of RNA and Northern blot analysis}

Total cellular RNA was isolated from $\sim 3 \times 10^{7}$ cells by the RNAzol method (Cinna/Biotex), and poly(A) ${ }^{+}$RNA was selected from 100-150 $\mu \mathrm{g}$ of total cellular RNA by oligo(dT)-cellulose column chromatography. The RNAzol method is based on the procedure described by Chomezynski and Sacchi (1987). In brief, cells were lysed by the addition of RNAzol, and the lysate was passed several times through a pipette. After addition of 0.1 volume of chloroform and centrifugation, the upper aqueous phase was transferred into a fresh tube containing an equal volume of isopropanol. After $45 \mathrm{~min}$ at $-20^{\circ} \mathrm{C}$, the RNA was pelleted and dissolved in $1 \mathrm{mM}$ EDTA $(\mathrm{pH} 7.0)$. Poly $(\mathrm{A})^{+}$ RNAs $(1 \mu \mathrm{g} / \mathrm{lane})$ were separated by electrophoresis on $1 \%$ agarose gels containing $2.2 \mathrm{M}$ formaldehyde, and transferred onto Hybond- $\mathrm{N}$ membranes (Amersham). Before blotting, the gel was soaked for $15 \mathrm{~min}$ in $50 \mathrm{~mm} \mathrm{NaOH}$ in $1 \times \mathrm{SSC}$ followed by two $10 \times$ SSC washes. The filters were hybridized with $\sim 1.5 \times 10^{7} \mathrm{cpm}$ probe with a sp. act. of $3 \times 10^{8}$ to $4 \times 10^{8}$ $\mathrm{cpm} / \mu \mathrm{g}$ DNA. Hybridization was carried out in a solution containing $50 \%$ formamide, $5 \times$ SSC, $20 \mathrm{mM}$ sodium phosphate (pH 6.7), 7\% SDS, $1 \%$ PEG-20,000, and $0.5 \%$ nonfat powdered milk at $42^{\circ} \mathrm{C}$ overnight. After hybridization, filters were washed twice at room temperature in $2 \times$ SSC, $1 \%$ SDS, followed by $0.2 \times \mathrm{SSC}, 1 \% \mathrm{SDS}$, at $60^{\circ} \mathrm{C}$ for $30 \mathrm{~min}$, followed, in turn, by autoradiography. The DNA fragments used as hybridization probes were labeled with ${ }^{32} \mathrm{P}$ by the random-primer method (Amersham; Feinberg and Vogelstein 1983, 1984). The probes used for hybridization were as follows: LTR, 320-bp EcoRI D fragment from pSRA-2 (Delorbe et al. 1980); Jun, EcoRI-BamHI fragment of pJun. A chicken $\beta$-actin probe was purchased from Oncor. Relative amounts of RNA were quantitated by densitometry with an LKB 2222-020 Ultrascan XL laser densitometer and normalized to actin.

\section{Antibodies and affinity purification}

Affinity-purified rabbit serum against PEP 1 was obtained from Oncogene Science (Manhasset, New York). PEP 2 (Bos et al. 1988) was used as an immunogen to generate monoclonal antibodies after coupling to the carrier protein keyhole limpet hemocyanin $(\mathrm{KLH})$, and as a screening antigen for antibody-producing hybridoma when coupled to thyroglobulin (TG). Synthetic peptide was coupled to protein carrier as described previously (Bos et al. 1988). BALB/c mice were injected subcutaneously with $100 \mu \mathrm{g}$ of KLH-PEP 2 complex in complete Freund's adjuvant. Three booster injections of the same amount in incomplete Freund's adjuvant were given at weekly intervals. The mice were rested for 2 weeks before injection of $100 \mu \mathrm{g}$ of KLH-PEP 2 in PBS in the tail veins. Spleen cells were harvested 4 days after the final boost and fused with NS-1 myeloma. Hybridomas producing antibody against TG-PEP 2 were screened by ELISA and were isolated and recloned by limiting dilution (Harlow and Lane 1988). PEP 5 (CTLNLSDAASSLKPHLRNKN), corresponding to chicken c-Jun amino acids $39-57$, was coupled to rabbit serum albumin and rabbit polyclonal antibody generated as described previously for PEP 1 and PEP 2 (Bos et al. 1988). Antibodies were affinity-purified on an antigen column according to the techniques of Harlow and Lane (1988). TG-PEP 2 and TG-PEP 5 were each coupled to Affigel 10 (Bio-Rad) according to the manufacturer's recommended procedure. Monoclonal antibody $\alpha$ PEP 2 culture supernatant and rabbit serum $\alpha$ PEP 5 were incubated overnight at $4^{\circ} \mathrm{C}$ with PEP 2 and PEP 5 columns, respectively. Nonspecific antibodies were rinsed with 10 column volumes of $10 \mathrm{~mm}$ Tris- $\mathrm{HCl}(\mathrm{pH} 7.4)$, followed by 5 column volumes of $500 \mathrm{mM} \mathrm{NaCl}, 10 \mathrm{~mm}$ Tris- $\mathrm{HCl}$ (pH 7.4). Specific antibodies were eluted with $100 \mathrm{~mm}$ glycine $(\mathrm{pH} 2.5)$ and quickly neutralized with $1 \mathrm{M}$ Tris- $\mathrm{HCl}(\mathrm{pH} 8.0)$ in the collection vessel.

\section{Immunofluorescence}

Cells were seeded on glass coverslips and incubated overnight in culture medium. They were then fixed in $4 \%$ formaldehyde in $10 \mathrm{~mm}$ PBS for $10 \mathrm{~min}$ and permeabilized in $-20^{\circ} \mathrm{C}$ acetone for $3 \mathrm{~min}$. Coverslips were rinsed in PBS and incubated with affinity-purified antiserum in a humid chamber at room temperature for $30 \mathrm{~min}$. After three rinses in PBS, the coverslips were incubated at room temperature in FITC-conjugated antiIgG serum for $30 \mathrm{~min}$. The coverslips were rinsed again three times in PBS before mounting in Gelvatol (Monsanto) with 2.5\% 1,4-diazobicyclo-[2,2,2]-octane (DABCO, Sigma), prepared according to Heimer and Taylor (1974).

\section{Preparation of protein extracts and immunoblot analysis}

Total cell lysates were prepared from cells under agar overlay by pouring off the agar and washing the cells with Tris-buffered saline (TBS). Cells were trypsinized, counted with a hemocytometer, and centrifuged. The cell pellets were lysed in $2 \%$ SDS, $140 \mathrm{~mm}$ 2-mercaptoethanol, $60 \mathrm{~mm}$ Tris-HCl (pH 6.8), and $0.01 \%$ bromphenol blue and boiled for $5 \mathrm{~min}$. The lysates were clarified at $10,000 \mathrm{~g}$ for $10 \mathrm{~min}$ at $4^{\circ} \mathrm{C}$, and lysate from $2 \times 10^{6}$ cells was separated on $10 \%$ SDS-polyacrylamide gels and transferred to nitrocellulose. Membranes were blocked with a solution containing $0.01 \%$ Ficoll, $0.01 \%$ polyvinylpyrrolidone, $1.6 \%$ BSA, $150 \mathrm{~mm} \mathrm{NaCl}, 166 \mathrm{~mm}$ sodium borate $(\mathrm{pH} 8.2\}, 6$ mM sodium azide, $0.1 \%$ NP-40, and $3 \%$ chicken serum for $1 \mathrm{hr}$ at room temperature, after which affinity-purified antibody was incubated for $1 \mathrm{hr}$ at room temperature. The membranes were washed five times with TBS, $0.1 \%$ Tween 20 , and alkaline phosphatase-conjugated anti-rabbit IgG (Promega) was added and incubated as before. The membranes were washed as above and incubated in substrate solution: $100 \mathrm{mM}$ Tris- $\mathrm{HCl}(\mathrm{pH} 9.5)$, $100 \mathrm{mM} \mathrm{NaCl}, 5 \mathrm{mM} \mathrm{MgCl}, 3.3 \mathrm{mg} / \mathrm{ml}$ nitro blue tetrazolium and $1.65 \mathrm{mg} / \mathrm{ml}$ bromochloroindoyl phosphate.

\section{Transfection and focus assay}

Primary CEFs were seeded on $35-\mathrm{mm}$ six-well plates at a density of $5 \times 10^{5}$ cells per well. Cells were grown overnight in growth media containing $2 \mu \mathrm{g} / \mathrm{ml}$ polybrene. Subconfluent CEFs were transfected with $0.5 \mu \mathrm{g}$ of CsCl-purified Jun-RCAS plasmid DNA by the method of Kawai and Nishizawa (1984). After $12-18 \mathrm{hr}$, cells were overlayed and incubated at $37^{\circ} \mathrm{C}$ until foci developed (usually 7-14 days). Agar colony assays were as described previously (Bister et al. 1977).

\section{Acknowledgments}

This work was supported by U.S. Public Health Service research grants CA 42564 (P.K.V.) and CA51982 (T.J.B.) and grant 1951 from the Council for Tobacco Research (P.K.V.). We thank Stephen Hughes for his generous gift of CLA12NCO and RCAS, Melinda Loo, Camtu Nguyen, Jonathan Bradley, Lowell Bengero, and Louis Gordon for technical support, and Richard Stenberg for critical review of the manuscript. 
The publication costs of this article were defrayed in part by payment of page charges. This article must therefore be hereby marked "advertisement" in accordance with 18 USC section 1734 solely to indicate this fact.

\section{References}

Angel, P., K. Hattori, T. Smeal, and M. Karin. 1988a. The iun proto-oncogene is positively autoregulated by its product, Jun/AP-1. Cell 55: 875-885.

Angel, P., E.A. Allegretto, S.T. Okino, K. Hattori, W.J. Boyle, T. Hunter, and M. Karin. 1988b. Oncogene $j u n$ encodes a sequence-specific trans-activator similar to AP-1. Nature 332: $166-171$.

Angel P., M. Imagawa, R. Chiu, B. Stein, R.J. Imbra, H.J. Rahmsdorf, C. Jonat, P. Herrlich, and M. Karin. 1987. Phorbol ester-inducible genes contain a common cis element recognized by a TPA-modulated trans-acting factor. Cell 49: 729-739.

Ball, Jr., A.R., T.J. Bos, C. Löliger, L.P. Nagata, T. Nishimura, H. $\mathrm{Su}, \mathrm{H}$. Tsuchie, and P.K. Vogt. 1988. jun: Oncogene and transcription regulator. Cold Spring Harbor Symp. Quant. Biol. 53: 687-695.

Bartel, D.P., M. Sheng, L.F. Lau, and M.E. Greenberg. 1989. Growth factors and membrane depolarization activate distinct programs of early response gene expression: Dissociation of fos and jun induction. Genes Dev. 3: 304-313.

Bister, K., M.J. Hayman, and P.K. Vogt. 1977. Defectiveness of avian myelocytomatosis virus MC 29: Isolation of long-term nonproducer cultures and analysis of virus-specific polypeptide synthesis. Virology 82: 431-448.

Bohmann, D. and R. Tiian. 1989. Biochemical analysis of transcriptional activation by Jun: Differential activity of $\mathrm{c}$ - and v-Jun. Cell 59: 709-717.

Bohmann, D., A. Admon, D.R. Turner, and R. Tjian. 1989. Transcriptional regulation by the AP-1 family of enhancer binding proteins: A nuclear target for signal transduction. Cold Spring Harbor Symp. Quant. Biol. 53: 695-700.

Bohmann, D., T.J. Bos, T. Nishimura, P.K. Vogt, and R. Tjian. 1987. Human proto-oncogene c-jun encodes a protein with antigenic and enhancer binding properties of transcription factor AP-1. Science 238: 1386-1392.

Bos, T.J., F.J. Rauscher III, T. Curran, and P.K. Vogt. 1989. The carboxy terminus of the viral Jun oncoprotein is required for complex formation with the cellular Fos protein. Oncogene 4: $123-126$.

Bos, T.J., D. Bohmann, H. Tsuchie, R. Tjian, and P.K. Vogt. 1988. V-jun encodes a nuclear protein with enhancer binding properties of AP-1. Cell 52: 705-712.

Brenner, D.A., M.M. O'Hara, P. Angel, M. Chojkier, and M. Karin. 1989. Prolonged activation of jun and collagenase genes by tumor necrosis factor- $\alpha$. Nature 337: 661-663.

Cavalieri F., T. Ruscio, R. Tiknoco, S. Benedict, C. Davis, and P.K. Vogt. 1985. Isolation of three new avian sarcoma viruses: ASV 9, ASV 17 and ASV 25. Virology 143: 680-683.

Chomezynski, P. and N. Sacchi. 1987. Single-step method of RNA isolation by acid guanidium thiocyanate-phenolchloroform extraction. Anal. Biochem. 162: 156-159.

Cohen, D.R. and T. Curran. 1988. fra-1: A serum-inducible, cellular immediate-early gene that encodes a Fos-related antigen. Mol. Cell. Biol. 8: 2063-2069.

Cohen, D.R., P.C.P. Ferreira, R. Gentz, B.R. Franza, Jr., and T. Curran. 1989. The product of a fos-related gene, fra-1, binds cooperatively to the AP-1 site with Jun: Transcription factor AP-1 is comprised of multiple protein complexes. Genes Dev. 3: $173-184$.
Curran, T., R.J. Rauscher III, D.R. Cohen, and R. Franza, Jr. 1989. Beyond the second messengers: Oncogenes and transcription factors. Cold Spring Harbor Symp. Quant. Biol. 53: 769-778.

DeLorbe, W.J., P.A. Luciw, H.M. Goodman, H.E. Varmus, and J.M. Bishop. 1980. Molecular cloning and characterization of avian sarcoma virus circular DNA molecules. I. Virol. 36: $50-61$

Feinberg, A.P. and B. Vogelstein. 1983. A technique for radiolabeling DNA restriction endonuclease fragments to high specific activity. Anal. Biochem. 132: 6-13.

1984. ADDENDUM A technique for radiolabeling DNA restriction endonuclease fragments to high specific activity. Anal. Biochem. 137: 266-267.

Gentz, R., R.J. Rauscher III, C. Abate, and T. Curran. 1989. Parallel association of Fos and Jun leucine zippers juxtaposes DNA binding domains. Science 243: 1695-1699.

Halazonetis, T.D., K. Georgopoulos, M.E. Greenberg, and P. Leder. 1988. c-Jun dimerizes with itself and with c-Fos, forming complexes of different DNA binding affinities. Cell 55: 917-924.

Harlow, E. and D. Lane. 1988. Antibodies: A laboratory manual. Cold Spring Harbor Laboratory, Cold Spring Harbor, New York.

Heimer, G.V. and C.E.D. Taylor. 1974. Improved mountant for immunofluorescence preparations. I. Clin. Pathol. 27: 254256.

Hirai, S.-I., R.-P. Ryseck, F.M. Bravo, and M. Yaniv. 1989. Characterization of jun D: A new member of the jun protooncogene family. $E M B O$ /. 8: 1433-1439.

Hughes, S. and E. Kosik. 1984. Mutagenesis of the region between env and src of the SR-A strain of Rous sarcoma virus for the purpose of constructing helper-independent vectors. Virology 136: 89-99.

Hughes, S., J.J. Greenhouse, C.J. Petropoulos, and P. Sutrave. 1987. Adapter plasmids simplify the insertion of foreign DNA into helper-independent retroviral vectors. J. Virol. 61: 3004-3012.

Imler, J.L., C. Schatz, C. Wasylyk, B. Chatton, and B. Wasylyk 1988. A Harvey-ras responsive transcription element is also responsive to a tumor-promoter and to serum. Nature 332: $275-276$.

Kawai, S. and M. Nishizawa. 1984. New procedure for DNA transfection with polycation and dimethyl sulfoxide. Mol. Cell. Biol. 4: 1172-1174.

Kouzarides, T. and E. Ziff. 1988. The role of the leucine zipper in the fos-jun interaction. Nature 336: 646-651.

Lamph, W.W., P. Wamsley, P. Sassone-Corsi, and I. Verma. 1988. Induction of proto-oncogene JUN/AP-1 by serum and TPA. Nature 334: 629-631.

Lee, W.M., C. Lin, and T. Curran. 1988. Activation of the transforming potential of the human fos proto-oncogene requires message stabilization and results in increased amounts of partially modified fos protein. Mol. Cell. Biol. 8: 55215527.

Lee, W., P. Mitchell, and R. Tjian. 1987a. Purified transcription factor AP-1 interacts with TPA-inducible enhancer elements. Cell 49: 741-752.

Lee, W., A. Haslinger, M. Karin, and R. Tjian. 1987b. Activation by two factors that bind promoter and enhancer sequences of the human metallothionein gene and SV40. Nature 325: $368-372$.

Lüscher, B., E. Christenson, D.W. Litchfield, E.G. Kribs, and R.N. Eisenman. 1990. Myb DNA binding inhibited by phosphorylation at a site deleted during oncogenic activation. Nature 344: 517-522. 
Maki, Y., T.J. Bos, C. Davis, M. Starbuck, and P.K. Vogt. 1987. Avian sarcoma virus 17 carries the jun oncogene. Proc. Natl. Acad. Sci. 84: 2848-2852.

Nakabeppu, Y., K. Ryder, and D. Nathans. 1988. DNA binding activities of three murine Jun proteins: Stimulation by Fos. Cell 55: 907-915.

Nishimura, T. and P.K. Vogt. 1988. The avian cellular homolog of the oncogene jun. Oncogene 3: 659-663.

Pertovaara, L., L. Sistonen, T.J. Bos, P.K. Vogt, J. Keski-Oja, and K. Alitalo. 1989. Enhanced jun gene expression is an early genomic response to transforming growth factor $\beta$ stimulation. Mol. Cell. Biol. 9: 1255-1262.

Quantin, B. and R. Breathnach. 1988. Epidermal growth factor stimulates transcription of the c-jun proto-oncogene in rat fibroblasts. Nature 334: 538-542.

Rauscher III, F.J., P.J. Voulalas, B.R. Franza, Jr., and T. Curran. 1988a. Fos and Jun bind cooperatively to the AP-1 site: Reconstitution in vitro. Genes Dev. 2: 1687-1699.

Rauscher III, F.J., D.R. Cohen, T. Curran, T.J. Bos, P.K. Vogt, D. Bohmann, R. Tjian, and B.R. Franza, Jr. 1988b. Fos-associated protein p39 is the product of the jun proto-oncogene. Science 240: 1010-1016.

Ryder, K. and D. Nathans. 1988. Induction of proto-oncogene c-jun by serum growth factors. Proc. Natl. Acad. Sci. 85: $8464-8467$.

Ryder, K., L.F. Lau, and D. Nathans. 1988. A gene activated by growth factors is related to the oncogene v-jun. Proc. Natl. Acad. Sci. 85: 1487-1491.

Schönthal, A., P. Herrlich, H.J. Rahmsdorf, and H. Ponta. 1988. Requirement for fos gene expression in the transcriptional activation of collagenase by other oncogenes and phorbol esters. Cell 54: 325-334.

Schütte, J., J.D. Minna, and M.J. Birrer. 1989. Deregulated expression of human c-jun transforms primary rat embryo cells in cooperation with an activated c-Ha-ras gene and transforms Rat-1a cells as a single gene. Proc. Natl. Acad. Sci. 86: 2257-2261.

Shaw, G. and R. Kaman. 1986. A conserved AU sequence from 3' untranslated region of GM-CSF mRNA mediates selective mRNA degradation. Cell 46: 659-667.

Shyu, A.-B., M.E. Greenberg, and J.G. Belasco. 1989. The c-fos transcript is targeted for rapid decay by two distinct mRNA degradation pathways. Genes Dev. 3: 60-72.

Sistonen, L., E. Holtta, T.P. Makela, J. Keski-Oja, and K. Alitalo. 1989. The cellular response to induction of the $\mathrm{p} 21^{\mathrm{c}-\mathrm{Ha} \text {-ras }}$ oncoprotein includes stimulation of jun gene expression. EMBO /. 8: 815-827.

Turner, R. and R. Tjian. 1989. Leucine repeats and an adjacent DNA binding domain mediate the formation of functional c-Fos-c-Jun heterodimers. Science 243: 1689-1694.

Vogt, P.K. and T.J. Bos. 1989. The oncogene jun and nuclear signalling. Trends Biochem. Sci. 14: 172-175.

- 1990. Jun: Oncogene and transcription factor. $A d v$. Cancer Res. 55: 1-35.

Zerial, M., L. Toschi, R.P. Ryseck, M. Schuermann, R. Muller, and R. Bravo. 1989. The product of a novel growth factor activated gene, fos $B$, interacts with JUN proteins enhancing their DNA binding activity. $E M B O J$. 8: 805-813. 


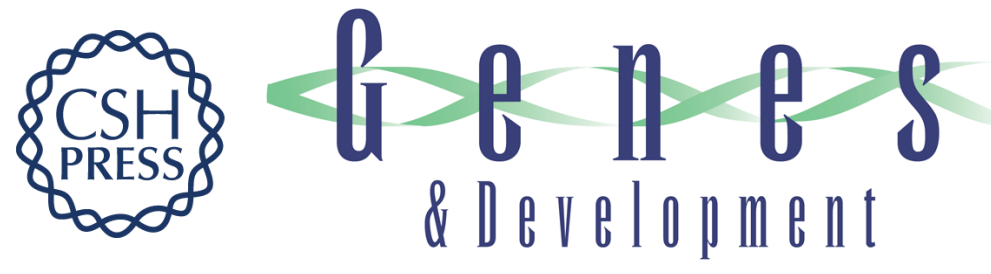

\section{Efficient transformation of chicken embryo fibroblasts by c-Jun requires structural modification in coding and noncoding sequences.}

T J Bos, F S Monteclaro, F Mitsunobu, et al.

Genes Dev. 1990, 4:

Access the most recent version at doi:10.1101/gad.4.10.1677

References This article cites 52 articles, 20 of which can be accessed free at:

http://genesdev.cshlp.org/content/4/10/1677.full.html\#ref-list-1

License

Email Alerting

Service

Receive free email alerts when new articles cite this article - sign up in the box at the top right corner of the article or click here.

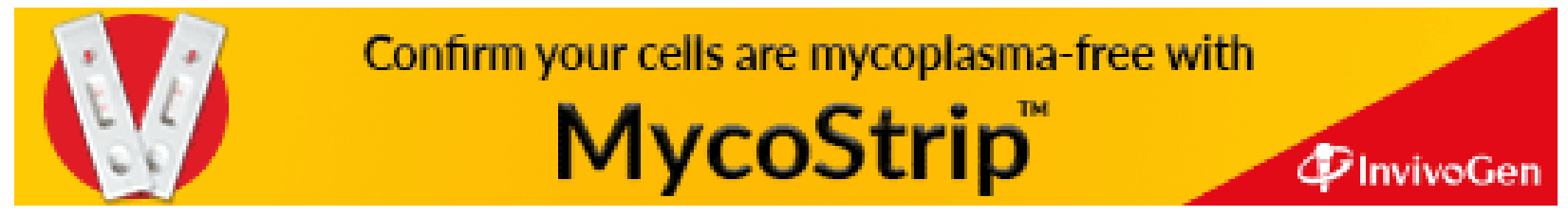

